\title{
Role of angiogenesis in endometriosis
}

\author{
Milena Kralickova ${ }^{1,2,3}$ and Vaclav Vetvicka ${ }^{4^{*}}$
}

*Correspondence: vaclav.vetvicka@louisville.edu

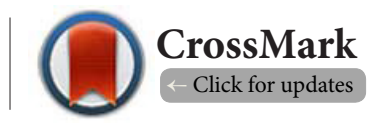

\begin{abstract}
'Department of Histology and Embryology, Faculty of Medicine, Charles University, Czech Republic, Europe. 2Department of Obstetrics and Gynecology, University Hospital, Faculty of Medicine, Charles University, Czech Republic, Europe. ${ }^{3}$ Biomedical Centre, Faculty of Medicine in Plzen, Charles University, Czech Republic, Europe.

${ }^{4}$ Department of Pathology, University of Louisville, Louisville, USA.
\end{abstract}

\begin{abstract}
Endometriosis is serious gynecological disease affecting millions of women world- wide. Despite long periods of intensive studies, the exact mechanisms are still unclear and no cure is in sight. Recently, the theory of angiogenesis being essential for the development and establishment of endometriosis is gaining more and more traction. This article covers not only angiogenesis in general, but also all major parts of angiogenesis found in endometriosis, including miRNA, VEGF, macrophages, inhibitors, and other approaches. This review is focused on present knowledge of the possible involvement of angiogenesis in development and possible treatment of endometriosis.
\end{abstract}

Keywords: Angiogenesis, endometriosis, microRNA, treatment

\section{Introduction}

Endometriosis is chronic inflammatory disease characterized by implantation and subsequent proliferation of endometrial tissue outside the uterine cavity. Etiology and pathogenesis of this disease remain unclear despite decades of intensive research [1]. This complex disease affecting 10-15\% of women in reproductive age has strong effects on the life of many women with a $30 \%$ prevalence of infertility. In addition, the risk of development of ovarian cancer cannot be overlooked [2]. Despite the ongoing interest of scientists and physicians, the exact pathogenic mechanisms of endometriosis remain unknown since von Rokitonsky used this term in 1860 [3]. For a recent overview of the most common hypothesis on endometriosis pathogenesis, see [4]. Among numerous theories, immunological aspects (for review see [5] or stem cells [6] have been suggested, but no prominent cause has been found. There are several optional treatments, including surgical or hormonal, but none of those represent a cure. The aim of this article is to summarize the current hypothesis about the role of angiogenesis in development of endometriosis.

\section{Review \\ Angiogenesis}

Angiogenesis is a biological process that plays an essential role in reproduction, development and repair. Generally, it is formation of new blood vessels from preexisting vasculature. In adults, angiogenesis is necessary for wound healing and development and action of female reproductive organs. A wide variety of angiogenic and anti-angiogenic factors has been described. The most important angiogenic factors include vascular endothelial growth factor (VEGF) family [7], angiopoietins, EGF, TGF-a and FGF, the most important anti-angiogenic factors are angiostatin, endostatin, and trombospondin (for review see [8]. Their effects are manifested by both overproduction of positive factors or by down-regulation of angiogenesis inhibitors.

Experimental studies of several antiangiogenic agents demonstrated the regression of endometriotic lesions by reducing their blood supply. As tissues growth, endometriotic implants require significant neovascularization to guarantee oxygen and essential nutrient supply. A typical clinical feature of endometriotic lesions is their dense vascularization. Angiogenesis plays an essential role in the growth and survival of endometriotic lesions. Numerous peritoneal blood vessels are observed around the active endometriotic lesions at laparoscopy and the implant itself is strongly vascularized under histological examination. Moreover, increased angiogenic activity has been demonstrated in peritoneal fluid from women with endometriosis and strong expression of angiogenic factors has been shown in active lesions. Further evidence of angiogenesis in the pathogenesis of endometriosis is provided by studies on animal models. 
Kralickova et al. Pathology Discovery 2016,

It is well established that endometriotic lesions need to gain a new blood supply to survive in ectopic sites, making angiogenesis essential for the development and establishment of endometriosis [9]. Menstrual cycle phase has a significant effect on vessel segment length, both within each region and within uterus layers.

More and more studies suggest the potential role of angiogenesis in endometriotis lesions and with findings that eutopic endometrium is a rich source of angiogenic factors [10], it was important to prepare a solid range of animal models. This is particularly true when promising anti-angiogenic compounds are tested. An up-to-date review of the best animal models [11] will be helpful to anybody trying to evaluate possible palliative agents.

As pathological angiogenesis can occur in wide range of disease, it is not surprising that angiogenesis is one of the processes that were shown to be closely associated with endometriosis. In normal conditions, vasculature is maintained by balances of both angiogenic and anti-angiogenic factors. However, in endometriosis, this balance is shifted toward increased expression of angiogenic inducers.In addition, dense vascularization is a classical pathological feature of this disease, leading to the hypothesis that anti-angiogenesis therapy might offer new ways on how to treat endometriosis [12]. This theory is based on studies suggesting that endometriosis might be an angiogenesis-dependent disease [13].

Processes of angiogenesis play a significant role in endometrial growth as well as in several gynecological disorders including endometriosis. Menstrual cycle phase has strong effects on vessel segment length, within each region as well as within each of the uterus layers. In endometrial layers, vessel length and branch point densities were greater in the fundal than the isthmic regions, regardless of the phase of the menstrual cycle. At the same time, vessel segment lengths were the greatest in the isthmic region [14].

In addition, angiogenesis is involved in cancer arising from endometriosis. VEGF has been detected in almost all samples of these cancers, in strong contrast to the presence in nonendometriosis-related cancers [15], suggesting that increase in VEGF detection might serve as a marker of tumor transformation. Increased angiogenic activity has been demonstrated in peritoneal fluid from patients with endometriosis. Similarly, significant expression of angiogenic factors has been shown in active lesions $[16,17]$.

\section{miRNA}

Some emerging data suggested that dysregulation of miRNA expression might play role in the development of endometriosis [18]. However, abnormal miRNA expression was implicated in the whole series of different pathologies, making theuse of miRNA in endometriosis difficult. An interesting work studied miRNA expression profiles of eutopic and ectopic endometrium and showed that miR-17-5 and miR-20a, involved in angiogenesis regulation, are down regulated in eutopic endometrium, which might be connected to upregulation of TSP-1 expression, reducing the angiogenic activity (for review see [19]. When endometrial and endometriotic cells were cultured with either control or endometriotic peritoneal fluid, the study revealed that in both cases peritoneal fluid significantly reduced all six miRNA levels regardless of the cell type used. In addition, both peritoneal fluids induced a strong increase of VEGF-A, UPA and PAI-1 protein level in all cultures. Endometrial cell cultures from patients treated with peritoneal fluid showed the same results. The authors suggested that the peritoneal fluid from patients with endometriosis modulates expression of miRNAs which change angiogenic and proteolytic balance [20]. The same group later determined the miRNA expression profiles in 51 patients with endometriosis. Compared to control women, patient endometrial tissue showed significantly lower levels of miR-202-3p, miR-424-5p, miR-449b-3p and miR-556-3p and higher levels of VEGF-A and UPA. Tissue affected by ovarian endometrioma showed lower expression of miR-449b-3p than endometrium from both control and patients, and significantly higher levels of PAI-I and angiogenic inhibitor TSP-I [20]. It is possible that these differences reflect the changes in the balance of angiogenic factors, but not enough information about targets of these miRNAs is currently available, making their use in diagnosis or therapy of endometriosis impossible.

\section{VEGF}

Recent data based on the direct effects of antiangiogenic agents added a new perspective in the mechanisms of their action. The most important agent is VEGF, as more than $80 \%$ of blood vessels in endometriosis implants are pericyte free and highly responsive to VEGF [12]. Besides VEGF, the broad spectrum of targets was found in the case of tyrosine kinase inhibitors, most of all in Sorafenib [21]. On the other hand, serum and urine VEGF levels in endometriosis patients do not differ from normal controls [22]. In addition, known polymorphisms in the VEGF gene might be responsible for the confusing results [23].

Compared to healthy women, in secretory phase endometrium from patients with endometriosis, we often find higher microvessel density, expression of VEGF-A in glandular epithelium and VEGFR-2 in endometrial blood vessels. The same can be mentioned about endometriotic lesions with high proliferative activity. It is hypothesized that severe dysregulation of angiogenic activity can represent an important factor [24].

Numerous studies suggested the role of angiogenesis inthe inhibition of endometriosis development. Many of those, however, offer only indirect proofs, often based on downregulation of anti-inflammatory factors such as VEGF levels or MMP9 activity [25]. On the other hand, some studies showed that direct treatment with angiostatic compounds such as endostatin or anti-VEGF antibody can inhibit established lesions $[\mathbf{1 0 , 2 6 ]}$. Expression of VEGF-C is higher in endometriotic tissues and 
is increasing with higher endometriosis grade. Treatment withthe anti-angiogenesis compound Endostar (new type of endothelin) reduced both volume and weight on lesions and significantly reduced VEGF-C expression [27]. The authors suggest that the expression of VEGF-C might serve as a marker of the efficacy of either anti-angiogenic or endiometric treatment.

Single ip.injection of bevacizumab (anti-VEGF antibody) causeda significant decrease of endometriotic lesions, lower adhesion scores, increased expression of Baxand decreased expression of $\mathrm{Bcl}-2$ genes. The authors interpreted these findings as proof that bevacizumab regresses endometriosis via anti-angiogenic mechanisms [28].

\section{Macrophages}

Macrophage migration inhibitory factor (MIF) is markedly elevated in vascularized and early-stage endometriotic lesions and acts like a mitogenic factor for endothelial cells. Further, studies revealed that exposure to MIF resulted in significant upregulation of VEGF, IL-8, and MCP-1 expression in endometriotic cells. A specific inhibitor of MIF abolished these effects. In addition, MIF was shown to promote its effects via CD44, CD74 and MAPK signaling pathways [29]. From these results we can conclude that MIF elicits an angiogenic phenotype in human ectopic endometrial cells and triggers the production of major angiogenic factors.

Tie-2-positive macrophages represent a subset of macrophages involved in promoting angiogenesis. In a mouse model, these macrophages infiltrated areas surrounding newly formed endometriotic blood vessels [30]. When these cells are depleted, endothelial cells do not organize effectively, making this subset of macrophages a solid target for potential treatment of endometriosis.

An interesting animal study showed that proangiogenic $\mathrm{Tie}^{+}$ macrophages infiltrate endometriotic lesions and dictate their growth. The expression of proangiogenic genes is probably critical for their support of endometrioticneovasculature [30].

\section{Inhibitors}

With so much attention focused on the role of angiogenesis in endometriosis, it is not surprising that many studies evaluated the possible effects of established or new inhibitors of individual angiogenetic factors.

Dienogest, which is a novel progestin selective for progesterone receptors, inhibits endometriosis via induction of apoptosis and strong reduction of angiogenesis [31], probably via attenuation of angiogenic factors such as VEFG and stromal cell-derived factor SDF-1.

Mouse models demonstrated that application of angiostatic compounds inhibit the growth of implants via disruptions of vascular supply [10]. Green tee catechin strongly inhibited the development of endometriosis by anti-angiogenic mechanisms [32]. Green tad-derived Epigallocatechin-3 (EGCG) is probably the most studied natural molecule expected to impact angiogenesis in endometriosis. Oral treatment significantly diminished proliferation and vascular density and increased apoptosis within the lesions [33].

Resveratrol also belongs among the commonly tested compounds. Four week oral treatment with resveratrol caused strong inhibition of angiogenesis in both peritoneal and mesenteric lesions. Immunohistochemical analysis showed that these findings might be caused by depressed proliferation of $\mathrm{CD} 31^{+}$endothelial cells [34]. The strong potential of resveratrol was also found in a rat model. Resveratrol-supplemented group showed strong reduction in the implant side, decreased levels of VEGF in plasma and peritoneum and decreased levels of MCP-1 [35]. Similarly to other angiogenic factors, inhibition of galectin- 1 by specific antibodies can decrease the severity of endometriosis [36].

Interesting, but potentially less important than animal studies is the report using human endometrial cell line. Bioactive fraction of Phaleria macrocarpa was shown to inhibit angiogenesis, downregulate estrogen receptor expression and inhibit eicosanoid signaling pathway by reducing NFkB transcription level [37].

P-selectin deficiency strongly inhibited the development of endometriosis in a mouse model. Treatment with soluble P-selectin reduced the size of lesions via angiogenetic processes, suggesting that P-selection might be a potential therapeutic target [38]. This compound has its effects mostly via lowering neutrophils and platelet adhesion, macrophage accumulation and neointimal formation after arterial injury.

The problem is that the use of anti-angiogenic factors or inhibiting the angiogenic factors only partially mitigated the development of endometriosis, making the use in clinical practice difficult. So far, nobody has tested the possible effects of a cocktail of inhibitors of angiogenesis.

\section{Other approaches}

Results of animal studies are often confusing. Estrogen can be either anti-angiogenic or pro-angiogenic, progesterone increases angiogenesis. For the findings that the basalis has app. 5 times as many lymphatic vessels than the functionalis we currently have no explanation [39].

A different approach was used by [40]. These authors evaluated the effects of antiangiogenic treatment on endometriosis-associated nerve fibers and showed depression in numbers of immature blood vessels and microvascular density. In addition, the study revealed macrophage, mast cell and nerve fiber reduction [40].

\section{Conclusion}

The theory of angiogenesis being essential for the development and establishment of endometriosis is gaining more and more traction. Recently, numerous important reviews appeared in scientific literature. Readers seeking the comprehensive review of anti-angiogenic treatment strategies should seek paper written by [41].

The most studied angiogenetic processes in endometriois 
Kralickova et al. Pathology Discovery 2016,

are involvement of miRNA, role of VEGF, macrophages and possible inhibitors. Further evidence of angiogenesis in the pathogenesis of endometriosis originated from animal studies. Experiments involving implantation of endometrium in immunodeficient mice have shown that endometriotic lesions derive their blood supply from the surrounding vascular network. Another important avenue is the use of possible inhibitors.

Currently, it is not a question whether angiogenesis is involved, but how it is involved. So far, the knowledge of how endometriotic lesions acquire angiogenic ability remains unknown. The most promising for future treatment seems to be the use of anti-angiogenic factors. However, we often do not even know how to effectively use these factors, i.e., as a neo-adjuvants or post operation, or how long. Recent data suggested that it is not one change in angiogenenic of anti-angiogenic factor which will determine whether endometriotic lesions develop or not, it will be a total balance of these factors [42].

Therefore, despite the fact that at least some aspects of the angiogenesis-endometriosis connection are now a hot topic in endometriosis studies, we are still too far from using inhibition of angiogenesis for treatment of this disease. Further experimental studies including clinical trials, are necessary.

\section{Competing interests}

The authors declare that they have no competing interests.

\section{Authors' contributions}

\begin{tabular}{|l|c|c|}
\hline Authors' contributions & MK & VV \\
\hline Research concept and design & -- & -- \\
\hline Collection and/or assembly of data & $\checkmark$ & $\checkmark$ \\
\hline Data analysis and interpretation & -- & -- \\
\hline Writing the article & $\checkmark$ & $\checkmark$ \\
\hline Critical revision of the article & -- & $\checkmark$ \\
\hline Final approval of article & $\checkmark$ & $\checkmark$ \\
\hline Statistical analysis & -- & -- \\
\hline
\end{tabular}

\section{Acknowledgement}

We would like to thank Ms. Tassie Deppert for final editing.

\section{Publication history}

Senior Editor: Takuji Tanaka, Gifu University, Japan.

Received: 05-Nov-2015 Final Revised: 14-Dec-2015

Accepted: 30-Dec-2015 Published: 07-Jan-2016

\section{References}

1. Baldi A, Campioni M and Signorile PG. Endometriosis: pathogenesis, diagnosis, therapy and association with cancer (review). Oncol Rep. 2008; 19:843-6. I Article I PubMed

2. Kralickova M, Losan $P$ and Vetvicka V. Endometriosis and cancer. Womens Health (Lond Engl). 2014; 10:591-7. I Article I PubMed

3. Von Rokitanski C. Uber Uterusdrusen-Neuerbildung in Uterus und Ovarilsarcomen. Z. GesselschaftAerzte Wien. 1860; 37:577-593.

4. Vetvicka $V$ and Kralickova M. Current theories on endometriosis pathogenesis. Endorium J. Mol. Pathol. 2015; 1:1-4.

5. Kralickova M and Vetvicka V. Immunological aspects of endometriosis: a review. Ann Trans/ Med. 2015; 3:153. | Article | PubMed Abstract | PubMed FullText

6. Kralickova M and Vetvicka V. Endometriosis: Are stem cells involved? Int. J. Clin. Exp. Med. Sci. 2015; 1:65-69.

7. Jeong SJ, Koh W, Lee EO, Lee HJ, Bae H, Lu J and Kim SH. Antiangiogenic phytochemicals and medicinal herbs. Phytother Res. 2011; 25:1-10. | Article I PubMed

8. Tahergorabi $Z$ and Khazaei $M$. A review on angiogenesis and its assays. Iran J Basic Med Sci. 2012; 15:1110-26. | PubMed Abstract I PubMed FullText

9. Rocha $A L$, Reis $F M$ and Taylor RN. Angiogenesis and endometriosis. Obstet Gynecol Int. 2013; 2013:859619. | Article | PubMed Abstract | PubMed FullText

10. Nap AW, Griffioen AW, Dunselman GA, Bouma-Ter Steege JC, Thijssen VL, Evers $\mathrm{JL}$ and Groothuis PG. Antiangiogenesis therapy for endometriosis. J Clin Endocrinol Metab. 2004; 89:1089-95. I Article I PubMed

11. Edwards AK, Nakamura DS, Virani S, Wessels JM and Tayade C. Animal models for anti-angiogenic therapy in endometriosis. J Reprod Immunol. 2013; 97:85-94. | Article | PubMed

12. Hull ML, Charnock-Jones DS, Chan CL, Bruner-Tran KL, Osteen KG, Tom BD, Fan TP and Smith SK. Antiangiogenic agents are effective inhibitors of endometriosis. J Clin Endocrinol Metab. 2003; 88:2889-99. | Article | PubMed

13. Taylor RN, Lebovic DI and Mueller MD. Angiogenic factors in endometriosis. Ann N Y Acad Sci. 2002; 955:89-100; discussion 118, 396 406. | Article | PubMed

14. Manconi F, Kable EP, Dwarte D, Jones A, Russell P, Chullapram T, Gange PV, Obeysekara S, Thomas GA and Fraser IS. Three dimensional microvascular measurements in human endometrium using optical slices from laser scanning confocal microscopy (LSCM). Micron. 2011; 42:853-62. | Article | PubMed

15. Del Carmen MG, Smith Sehdev AE, Fader AN, Zahurak ML, Richardson M, Fruehauf JP, Montz FJ and Bristow RE. Endometriosis-associated ovarian carcinoma: differential expression of vascular endothelial growth factor and estrogen/progesterone receptors. Cancer. 2003; 98:1658-63. | Article | PubMed

16. Nisolle M, Casanas-Roux F, Anaf V, Mine JM and Donnez J. Morphometric study of the stromal vascularization in peritoneal endometriosis. Fertil Steril. 1993; 59:681-4. I Article I PubMed

17. Donnez J, Smoes P, Gillerot S, Casanas-Roux F and Nisolle M. Vascular endothelial growth factor (VEGF) in endometriosis. Hum Reprod. 1998; 13:1686-90. | Article | PubMed

18. Pan Q, Luo X, Toloubeydokhti T and Chegini N. The expression profile of micro-RNA in endometrium and endometriosis and the influence of ovarian steroids on their expression. Mol Hum Reprod. 2007; 13:797806. I Article I PubMed

19. Mari-Alexandre J, Garcia-Oms J, Barcelo-Molina M, Gilabert-Aguilar J, Estelles A, Braza-Boils A and Gilabert-Estelles J. MicroRNAs and angiogenesis in endometriosis. Thromb Res. 2015; 135 Suppl 1:S38-40. | Article I PubMed

20. Braza-Boils A, Gilabert-Estelles J, Ramon LA, Gilabert J, MariAlexandre J, Chirivella M, Espana F and Estelles A. Peritoneal fluid reduces angiogenesis-related microRNA expression in cell cultures of endometrial and endometriotic tissues from women with endometriosis. PLoS One. 2013; 8:e62370. | Article | PubMed Abstract | PubMed FullText

21. Pittatore G, Moggio A, Benedetto C, Bussolati B and Revelli A. Endometrial adult/progenitor stem cells: pathogenetic theory and new antiangiogenic approach for endometriosis therapy. Reprod Sci. 2014; 21:296-304. | Article | PubMed

22. Gagne D, Page M, Robitaille G, Hugo P and Gosselin D. Levels of vascular endothelial growth factor (VEGF) in serum of patients with endometriosis. Hum Reprod. 2003; 18:1674-80. I Article I PubMed

23. Kim SH, Choi YM, Choung SH, Jun JK, Kim JG and Moon SY. Vascular endothelial growth factor gene $+405 \mathrm{C} / \mathrm{G}$ polymorphism is associated with susceptibility to advanced stage endometriosis. Hum Reprod. 2005; 
Kralickova et al. Pathology Discovery 2016,

\section{0:2904-8. | Article | PubMed}

24. Bourlev V, Volkov N, Pavlovitch S, Lets N, Larsson A and Olovsson M. The relationship between microvessel density, proliferative activity and expression of vascular endothelial growth factor-A and its receptors in eutopic endometrium and endometriotic lesions. Reproduction. 2006; 132:501-9. | Article | PubMed

25. Xu Z, Zhao F, Lin F, Chen J and Huang Y. Lipoxin A4 inhibits the development of endometriosis in mice: the role of anti-inflammation and anti-angiogenesis. Am J Reprod Immunol. 2012; 67:491-7. | Article I PubMed

26. Dabrosin C, Gyorffy S, Margetts P, Ross C and Gauldie J. Therapeutic effect of angiostatin gene transfer in a murine model of endometriosis. Am J Pathol. 2002; 161:909-18. | Article | PubMed Abstract | PubMed FullText

27. Song WW, Lu H, Hou WJ, Xu GX, Zhang JH, Sheng YH, Cheng MJ and Zhang R. Expression of vascular endothelial growth factor $C$ and antiangiogenesis therapy in endometriosis. Int J Clin Exp Pathol. 2014; 7:7752-9. | PubMed Abstract | PubMed FullText

28. Soysal D, Kizildag S, Saatli B, Posaci C, Soysal S, Koyuncuoglu M and Dogan $\mathrm{O}$. A novel angiogenesis inhibitor bevacizumab induces apoptosis in the rat endometriosis model. Balkan J Med Genet. 2014; 17:73-80. | Article | PubMed Abstract | PubMed FullText

29. Veillat V, Carli C, Metz CN, Al-Abed Y, Naccache PH and Akoum A. Macrophage migration inhibitory factor elicits an angiogenic phenotype in human ectopic endometrial cells and triggers the production of major angiogenic factors via CD44, CD74, and MAPK signaling pathways. J Clin Endocrinol Metab. 2010; 95:E403-12. | Article | PubMed

30. Capobianco A, Monno A, Cottone L, Venneri MA, Biziato D, Di Puppo F, Ferrari S, De Palma M, Manfredi AA and Rovere-Querini P. Proangiogenic Tie2(+) macrophages infiltrate human and murine endometriotic lesions and dictate their growth in a mouse model of the disease. Am J Pathol. 2011; 179:2651-9. | Article | PubMed Abstract | PubMed FullText

31. Miyashita M, Koga K, Takamura M, Izumi G, Nagai M, Harada M, Hirata T, Hirota Y, Fujii T and Osuga Y. Dienogest reduces proliferation, aromatase expression and angiogenesis, and increases apoptosis in human endometriosis. Gynecol Endocrinol. 2014; 30:644-8. | Article | PubMed

32. Xu H, Lui WT, Chu CY, Ng PS, Wang CC and Rogers MS. Anti-angiogenic effects of green tea catechin on an experimental endometriosis mouse model. Hum Reprod. 2009; 24:608-18. | Article | PubMed

33. Ricci AG, Olivares CN, Bilotas MA, Baston JI, Singla JJ, Meresman GF and Baranao RI. Natural therapies assessment for the treatment of endometriosis. Hum Reprod. 2013; 28:178-88. | Article I PubMed

34. Rudzitis-Auth J, Menger MD and Laschke MW. Resveratrol is a potent inhibitor of vascularization and cell proliferation in experimental endometriosis. Hum Reprod. 2013; 28:1339-47. | Article | PubMed

35. Ergenoglu AM, Yeniel AO, Erbas O, Aktug $\mathrm{H}$, Yildirim N, Ulukus $\mathrm{M}$ and Taskiran D. Regression of endometrial implants by resveratrol in an experimentally induced endometriosis model in rats. Reprod Sci. 2013; 20:1230-6. | Article | PubMed

36. Baston JI, Baranao RI, Ricci AG, Bilotas MA, Olivares CN, Singla JJ, Gonzalez AM, Stupirski JC, Croci DO, Rabinovich GA and Meresman GF. Targeting galectin-1-induced angiogenesis mitigates the severity of endometriosis. J Pathol. 2014; 234:329-37. | Article | PubMed

37. Tandrasasmita OM, Sutanto AM, Arifin PF and Tjandrawinata RR. Anti-inflammatory, antiangiogenic, and apoptosis-inducing activity of DLBS1442, a bioactive fraction of Phaleria macrocarpa, in a RL95-2 cell line as a molecular model of endometriosis. Int J Womens Health. 2015; 7:161-9. | Article | PubMed Abstract | PubMed FullText

38. Guo SW, Ding D, Geng JG, Wang L and Liu X. P-selectin as a potential therapeutic target for endometriosis. Fertil Steril. 2015; 103:990-1000 e8. | Article | PubMed

39. Rogers PA, Donoghue JF, Walter LM and Girling JE. Endometrial angiogenesis, vascular maturation, and lymphangiogenesis. Reprod Sci. 2009; 16:147-51. | Article | PubMed

40. Novella-Maestre E, Herraiz S, Vila-Vives JM, Carda C, Ruiz-Sauri A and Pellicer A. Effect of antiangiogenic treatment on peritoneal endometriosis-associated nerve fibers. Fertil Steril. 2012; 98:1209-17. |
Article I PubMed

41. Laschke MW and Menger MD. Anti-angiogenic treatment strategies for the therapy of endometriosis. Hum Reprod Update. 2012; 18:682-702. | Article | PubMed

42. Becker CM and D'Amato RJ. Angiogenesis and antiangiogenic therapy in endometriosis. Microvasc Res. 2007; 74:121-30. | Article | PubMed

\section{Citation:}

Kralickova M and Vetvicka V. Role of angiogenesis in endometriosis. Pathol Discov. 2016; 4:1.

http://dx.doi.org/10.7243/2052-7896-4-1 